\title{
Más que superhéroes: filosofía del lenguaje, perennialismo y los cimientos de la realidad en Grant Morrison
}

\section{More than superheroes: language philosophy, perennialism and the foundations of reality in Grant Morrison}

\author{
Mario Ramos Vera
}

(Universidad Pontificia Comillas)

Mario Ramos Vera es doctor en Filosofía (con premio extraordinario 2016-2017). Primer premio de ensayo del xxx «Memorial Florencio Segura» 2016. Acreditado como Profesor Ayudante Doctor (ANECA). Profesor del departamento de Filosofía y Humanidades de la Universidad Pontificia Comillas y docente en ESNE, Escuela Universitaria de Diseño, Innovación y Tecnología; ha sido profesor invitado en el Instituto Teológico Lucense. Licenciado en Derecho y en Ciencia Política (UAM), diplomado en Ciencias Religiosas (Universidad Eclesiástica San Dámaso), máster en Filosofía Teórica y Práctica (UNED), máster en Profesor de Secundaria y Bachillerato - especialidad de Filosofía - (Universidad Pontificia Comillas) y máster en Relaciones Internacionales (ALITER). Autor del libro La utopia conservadora (Universidad Pontificia Comillas, 2020), con más de treinta publicaciones académicas (capítulos de libros, artículos académicos, reseñas...) y evaluador de artículos académicos para revistas científicas. Sus ámbitos de investigación son el pensamiento utópico, las ideologías políticas, la historia de las ideas así como el pensamiento imaginativo y mitopoético.

Fecha de recepción: 29 de septiembre de 2020

Fecha de aceptación definitiva: 21 de noviembre de 2020 


\title{
Resumen
}

Los planteamientos especulativos que, desde el ámbito de la filosofía del lenguaje, ha propuesto el guionista de cómics y ensayista Grant Morrison resultan pertinentes y relevantes por su profundidad teórica. Por medio del género de superhéroes, concebido como vehículo narrativo, es posible acceder a una propuesta nítida que recurre a la filosofía del lenguaje para tantear una vertiente ontológica. Para ello, resulta pertinente abordar las relaciones que Morrison sugiere entre pensamiento y lenguaje, entre las palabras y los signos en su vínculo y correspondencia con la realidad. Desde una pluralidad de perspectivas, congruentes con su planteamiento posmoderno, el superhéroe es capaz de incardinar en sí mismo cuestiones filosóficas y lingüísticas de enorme trascendencia que han traslucido en todo momento y en todo lugar, con diferentes ropajes, para hacer llegar un mensaje ético y ontológico concreto.

Palabras clave: filosofía, Grant Morrison, posmodernidad, semántica, semiótica, superhéroe.

\begin{abstract}
The comic writer and essayist Grant Morrison has proposed speculative approaches, from the field of language philosophy, relevant because of their theoretical depth. Through the genre of superheroes, conceived as a narrative vehicle, it is possible to access a clear proposal that links the philosophy of language with the ontological dimension of philosophy. In that sense, I will address the relationships Morrison suggests between thought and language, between words and signs in their correspondence with reality. From a plurality of perspectives, consistent with its postmodern approach, as the author points out, the superhero becomes capable of incardinating in himself philosophical and linguistic issues of enormous importance that have transpired at all times and in all places, with different clothing, to convey a specifical ontologic and ethical message.
\end{abstract}

Keywords: Grant Morrison, philosophy, postmodernity, semantics, semiotics, superhero.

\section{Cita bibliográfica}

Ramos Vera, M. «Más que superhéroes: filosofía del lenguaje, perennialismo y los cimientos de la realidad en Grant Morrison», en CuCo, Cuadernos de cómic n. ${ }^{\circ} 15$ (2020), pp. 52-70. 


\section{Introducción y metodología}

«Preparaos para volveros ficticios». Con estas palabras de Lord Limbo —uno de los superhéroes aparecidos en el cómic Flex Mentallo- el guionista Grant Morrison (Glasgow, 1960) evidencia su vínculo con la filosofía del lenguaje y su conocimiento de los recursos estilísticos con el fin de sustanciar cuestiones filosóficas de relevancia. Por este motivo, es posible constatar que a través del cómic de superhéroes como vehículo narrativo Morrison reformula con hondura teórica las relaciones entre pensamiento y lenguaje, entre este y la realidad o entre las palabras y los signos. Desde un modalismo de enfoques propios de la filosofía del lenguaje que le acerca a la posmodernidad, Morrison excede un enclave teórico concreto para plantear cuestiones filosóficas de enorme trascendencia como la existencia de un plano metafísico de ideas con consistencia ontológica y el vínculo de estas con determinados conocimientos, virtudes e ideas que han traslucido en todo momento y en todo lugar, con diferentes ropajes. Este perennialismo y la ampliación de horizontes de idealidad que propone Morrison, aparece personificado en el superhéroe. Esta propuesta resulta relevante porque llena un hueco en las aproximaciones académicas a Morrison, habitualmente centradas en su filiación ideológica, en los estudios culturales y en su relación con el pensamiento esotérico occidental. ${ }^{1}$

Para dar respuesta a este planteamiento partiré de diversas obras de arte secuencial del autor estudiado: Animal Man, La Patrulla Condenada, Kid Eternity, Flex Mentallo, Los Invisibles, All-Star Superman o Klaus, que atestiguan la evolución del enfoque teórico de Morrison a lo largo de varias décadas y permiten trazar una perspectiva amplia. Resulta posible acreditar que, a juicio de Grant Morrison, los cómics de superhéroes forman parte de un caudal de conocimientos, arquetipos e ideas perennes. Desde un enfoque metodológico propio de las humanidades, las siguientes líneas aspiran a (1) exponer sintéticamente los planteamientos de la filosofía del lenguaje y la ontología en las obras seleccionadas; (2) contextualizarlos en el ámbito del pensamiento posmoderno del autor; (3) destacar la concreción filosófica de su propuesta en la figura del superhéroe; (4) desarrollar el esencialismo y perennialismo del concepto del superhéroe para Morrison y, por último (5), plantear unas sucintas conclusiones.

\footnotetext{
1 Morrison, G. Supergods. Héroes, mitos e historias del cómic. Madrid, Turner, 2012; Morrison, G. «Pop Magic!», en Metzger, R. (ed.). Book of Lies. Nueva York, Disinformation, 2003, pp. 16-25. Cfr. Asprem, E. «Contemporary Ritual Magic», en Partridge, C. (ed.). The Occult World. Nueva York, Routledge, 2015, pp. 382-396 y Granholm, K. «The Occult and Comics», en Partridge, C. (ed.). Op. cit., pp. 499-508.
} 


\section{Planteamientos filosóficos en las obras seleccionadas}

El criterio seguido en este artículo para dar a conocer los distintos enfoques que, desde la Filosofía del Lenguaje, ofrece Morrison en una selección de sus obras será cronológico-diacrónico. En consecuencia, las series analizadas serán Animal Man (1988-1990), La Patrulla Condenada (1989-1993), Kid Eternity (1991), Los Invisibles (1994-2000), Flex Mentallo (1996), All-Star Superman (2005-2008) y Klaus (20152016). Como es posible apreciar, esta selección comprende varias décadas dentro de la extensa producción intelectual de Grant Morrison.

\section{Animal Man}

Grant Morrison - acompañado de dibujantes como Chaz Truog y Tom Grummett - recuperaría en esta serie un personaje de Dave Wood y Carmine Infantino, cuya primera aparición tendría lugar en la serie de la editorial DC Strange Adventures en 1965. Acometería una relectura, un esfuerzo de profundización conceptual y una propuesta de carácter metanarrativo, especialmente en el n. ${ }^{\circ} 5$ de la serie, titulado elocuentemente «El evangelio del coyote», donde un animal antropomórfico - que evoca al personaje de una conocida serie de animación encargado de perseguir a un correcaminos- finalmente encuentra la muerte. Una muerte que, tal y como aparece en las viñetas finales, ha sido ocasionada por el pincel que atraviesa el cuarto muro, esto es, por la mano y el designio de un creador que excede el nivel literario. Esta propuesta metanarrativa impregna toda la serie pero culmina, muy especialmente, los n. ${ }^{\text {os }} 19$-donde el propio superhéroe reconoce al lector- y 25 y 26 - en los que Animal Man se encuentra con su creador, el propio guionista Grant Morrison.

Resulta evidente la alusión a Miguel de Unamuno, a su novela Niebla y a su personaje, que excede la condición de ente ficticio para interpelar a su creador, el propio literato devenido en personaje ficticio. A mayor abundamiento, Morrison reflexiona sobre la capacidad creadora del lenguaje, sobre su vis mitopoética como capacidad de construir mundos autocontenidos, a las teorías de la correspondencia que postulan un isomorfismo estructural y ontológico entre lenguaje y verdad, entre lenguaje y realidad. Así, la noción de verdad — que alude tanto a la filosofía del lenguaje como a la epistemología - se encontraría en la adecuación entre el objeto, el entendimiento y el lenguaje. ${ }^{2}$ De la relación entre lenguaje y creación se extraen sugerentes paralelismos con facetas como el lenguaje religioso, la hermenéutica y la propia caracterización de los contextos ficticios.

2 Conesa, F. y Nubiola, J. Filosofía del lenguaje. Herder, Barcelona, 2002, p. 152 y Llano, A. Teoría del conocimiento. Madrid, Biblioteca de Autores Cristianos, 2015, p. 134. 


\section{La Patrulla Condenada}

A diferencia de la serie anteriormente expuesta, La Patrulla Condenada puede ser considerada una serie de raigambre, aunque con cierto carácter excéntrico, de la editorial DC, creada en 1963 por Arnold Drake y Bruno Premiani. Desde que Morrison comenzó a guionizar esta serie en su n. ${ }^{\circ} 19$, la exploración de personajes alienados revestiría una reflexión sobre los vínculos entre ficción y realidad, entre las ideas —en su acepción griega de eidos como objeto con contenido propio-y la realidad sensible. En este caso, dar cuenta de todos y cada una de sus interrelaciones excedería el objetivo de estas líneas pero sí conviene aludir a la aparición de unos villanos pintorescos, la Hermandad del Dadá —originalmente en los n. ${ }^{\text {os }} 26-29$ y después en los n. ${ }^{\text {os }} 49$ 52-, vinculados en su aparente aleatoriedad, caos y sinsentido con el estilo artístico del que toman nombre, aunque en este caso, como némesis o contrapartidas de cada uno de los integrantes de la Patrulla Condenada. ${ }^{3}$

Más allá de la ruptura del convencionalismo lingüístico, de la quiebra del significado como objeto de estudio de la semántica, los villanos dadaístas suponen una referencia al vínculo entre lenguaje e ideas. Así lo reconoce su líder en el n.o 49, titulado «Muerte en Venecia»: sus ideas exceden las posibilidades expresivas del lenguaje. En última instancia, la convención no supone una cadena lo suficientemente férrea como para aprehender el potencial ontológico de las ideas, que precisan de lenguajes con mayores posibilidades expresivas, que excedan cualquier teoría del significado planteada desde el acuerdo humano. Este juego metalingüístico planteado por Morrison permite aludir a la base lingüística como un fundamento adicional de la realidad junto con los objetos físicos, lo que expresaría consecuencias epistemológicas, pues ese lenguaje alude a la realidad profunda de las ideas. Dicho horizonte supraempírico entroncaría indirectamente con una sensibilidad platónica propia de los planteamientos de Morrison.

\section{Kid Eternity}

Cito esta obra, que recupera un personaje propio de la edad de oro del cómic, en este caso un personaje de 1942 creado por Otto Binder y Sheldon Moldoff para la editorial Quality Comics, adquirida por DC varias décadas más tarde. En sus orígenes, este cómic aludía a un joven que se ahogaba varias décadas antes de la fecha prevista de su muerte, lo que permitía a los poderes angelicales devolverle a la vida como un héroe justiciero. Morrison reinventaría al personaje como un nihilista, peón en la batalla eterna entre los conceptos del caos y del orden, en un concepto cosmológico de viaje iniciático profundamente gnóstico y hermético.

\footnotetext{
${ }^{3}$ Singer, M. Grant Morrison. Combining the Worlds of Contemporary Comics. University Press of Mississippi, Jackson, 2012, p. 80.
} 
De este cómic, publicado en tres números en 1991, resultan especialmente relevantes tres viñetas concretas del tercer volumen. En ellas, uno de los rivales de Kid Eternity pregunta: «Dime el sentido de la palabra y deja que me alce extasiado». La respuesta de Kid Eternity es elocuente: «No hay significado. El sonido es el significado. Escucha. Eternidad». En este ejemplo, cabe apreciar uno de los principales problemas que estudia la filosofía del lenguaje, el triángulo semiótico que refleja la estructura triádica de los signos - que pone en conexión pensamiento (concepto), palabra (signo) y cosa (objeto) y que, en última instancia, estudia la interrelación entre sujeto, lenguaje y mundo.

En Kid Eternity, Grant Morrison evidencia un gnosticismo dualista que escinde los niveles de la realidad en distintos grados de complejidad en el ámbito de la materia y en el de las sustancias sutiles espirituales. Por ello, podemos deslindar en dos ámbitos las consecuencias de la afirmación del personaje protagonista. Desde la semiótica, alude a la relación entre pensamiento y lenguaje —es decir, hasta qué punto permanecemos ligados a lenguaje o si, por el contrario, es posible un pensamiento sin lenguaje- Desde una perspectiva semántica, alude al problema del significado, a la manera que tienen las palabras de «enganchar» $\mathrm{o}$ «conectar» con la realidad. Conviene exponer muy brevemente ambas apreciaciones.

Respecto a la primera, la dimensión semiótica de esta afirmación incide en las posibilidades que admite la relación entre pensamiento y lenguaje, a saber, el lenguaje traduce el pensamiento, lo determina o el primero es vehículo del segundo. ${ }^{4}$ En este sentido, parece que Kid Eternity hubiese rechazado de plano la primera y tercera opción, pues su afirmación niega que el lenguaje sea un código para la traducción del pensamiento o que este tenga un carácter fundante sobre el primero. En cambio, parece suscribir la tesis de Whorf, que postula que el pensamiento depende completamente del lenguaje. ${ }^{5}$ Este relativismo lingüístico condicionaría todo acceso a la realidad desde un punto de vista determinado. Por ese motivo, los signos son el acceso, otorgan el significado, confieren la consistencia ontológica.

Este aserto, no obstante, manifiesta también consecuencias semánticas, pues niega el significado, rechazando así la doctrina del atomismo lógico (Russell), la teoría figurativa del significado (Wittgenstein) o el significado como verificabilidad (Círculo de Viena). Parece abrazar el conductismo de Quine, que asevera que el lenguaje es una fábrica de la realidad, alejado de entes abstractos o definiciones intelectivas, ayunas de soporte empírico. ${ }^{6}$ En este planteamiento conductista, la semántica enseñaría a emplear el lenguaje para transformar la realidad circundante, algo similar a lo que

\footnotetext{
${ }^{4}$ Conesa, F. y Nubiola, J. Op. cit., pp. 87-98.

5 Whorf, B. L. Lenguaje, pensamiento y realidad. Barcelona, Barral, 1971, pp. 241-244.

${ }^{6}$ Quine, W. O. Palabra y objeto. Barcelona, Labor, 1968, pp. 39-102.
} 
hace Kid Eternity al convocar sus poderes preternaturales y que responde a los efectos performativos que el propio Morrison imputa a la magia.

\section{Los Invisibles}

La serie de Los Invisibles (1994-2000) ha sido considerada el manifiesto ocultista y posmoderno de Grant Morrison - en compañía de una pléyade de artistas entre los que cabe citar, por ejemplo, a Frank Quitely, Mark Buckingham o Phil Jiménez, entre otros- A lo largo de tres volúmenes, nos presenta los esfuerzos de una célula de magos anarquistas del Colegio Invisible - un término propio del ocultismo y del hermetismo con resonancias significativas - en su lucha para sanar la escisión maniquea de nuestra realidad impuesta por los arcontes oscuros y, de esta manera, recuperar la unidad originaria de los mundos del cuerpo y del espíritu. La fecundidad de ideas, planteamientos y fuentes de esta serie hace imposible abordar todas las alusiones a la filosofía del lenguaje, aunque es factible destacar dos especialmente significativas: (a) la existencia de un lenguaje primigenio con efectos ontológicos, tal y como recoge la Célula 23, y (b) la exaltación de la tesis del lenguaje como determinación del pensamiento, representada por la Llave 17.

En primer lugar, Morrison alude a la Célula 23 (a), una organización clandestina dentro del propio Colegio Invisible que actúa como vigilante de las demás células independientes y es capaz de purgar psíquicamente la contaminación de los invisibles. En el capítulo 13 del volumen 2, uno de sus efectivos declara que «la realidad es el lenguaje», y este, a su vez, no es sino una degradación de una lengua originaria, compuesta con un alfabeto con los sesenta y cuatro caracteres verdaderos. De esta manera, el lenguaje primigenio tendría capacidades operativas y ontológicas. Esta idea entraña reminiscencias de la Cábala hebrea o de las tesis de Descartes, Leibniz o Humboldt. ${ }^{7}$ No obstante, Morrison introduce un enfoque postestructuralista, pues la Célula 23 utiliza este lenguaje para alterar los centros de procesamiento del lenguaje, limpiar las psiques de los invisibles y simular experiencias cognitivas vívidas. $^{8}$

A continuación (b), la Llave 17 será un elemento recurrente a lo largo de la serie desde su aparición en el arco argumental «Entropía en el Reino Unido» y, finalmente, permitirá derruir la cárcel de la materia-impuesta por los arcontes oscurospara liberar a la humanidad. Se trata de una sustancia psicoactiva que literaliza el lenguaje, convirtiendo en real cualquier palabra: una enfermedad, un suceso, una onomatopeya... Esto es, la Llave 17 erosiona la escisión entre lenguaje y realidad,

7 Bustos Guadaño, E. Filosofía del lenguaje. Madrid, UNED, 1999, pp. 108-109 y 161-173.

${ }^{8}$ Neighly, P. y Cowe-Spigai, K. Anarchy for the Masses. The Disinformation Guide to The Invisibles. Nueva York, Disinformation, 2003, pp. 135-148 y Singer, M. Op. cit., p. 120. 
apuntala el argumento del poder del lenguaje para dar forma a nuestras percepciones. ${ }^{9}$ Supone conceder vigencia plena a la tesis de Sapir y Whorf, el relativismo lingüístico, que afirma que el lenguaje condiciona nuestra percepción de la realidad. El lenguaje ordena el mundo y configura nuestra realidad, no existiría algo así como un acceso imparcial al orden extramental. Morrison sublima la comunicación lingüística y simbólica, concediéndole efectos ontológicos radicales capaz de dictar las subjetividades. Signo y referente se homogeneizan, la verdad se fabrica, nos indica en Los Invisibles. Esta amalgama de posmodernidad y relativismo lingüístico permite que los invisibles operen por medio de metalenguajes que les garantizan un estatuto epistemológico privilegiado y un potencial ontológico de alcance preternatural en su misión de restaurar la unidad originaria perdida. Es decir, del regreso a la edad de oro.

\section{Flex Mentallo}

En Flex Mentallo Morrison planteó — junto al dibujante Frank Quitely— recuperar al «tipo de superhéroe de antes de la Edad Oscura [...]pero situado en un mundo más siniestro». ${ }^{10}$ Cada número de esta colección guardaba una relación temática y formal vinculada con cada edad del cómic (oro, plata, bronce y edad oscura) y el último vaticinaba la llegada de la nueva edad del cómic, una edad de sentido de maravilla y de grandeza heroica revestida de los ropajes de la posmodernidad. Este relato metaficcional entraña una propuesta ontológica: los superhéroes han existido no solo en los mitos, sino también en nuestra realidad. Nos han guiado, nos han guardado, pero una amenaza existencial les obligó a replegarse en el mundo de las ideas platónicas. ${ }^{11} \mathrm{~A}$ lo largo de varios niveles de narración - con planos narrativos superpuestos y tramas interrelacionadas - subyace un orden gradual y complejo que enhebra el mundo metahistóricamente.

A mayor abundamiento, la propuesta ontológica de Flex Mentallo viene acompañada de varias alusiones a la filosofía del lenguaje. Desde la primera viñeta de la primera página se inicia una secuencia en la que un villano arroja un explosivo del que brota un universo en eclosión y que, a su vez, vincula al universo ficticio en el que se desarrolla la serie a través de una narrativa secuencial. En el primer número de la serie, el protagonista debe aplicar sus poderes ontológicos del denominado «misterio muscular» para neutralizar un atentado terrorista. Además, a lo largo de los diversos números que componen este cómic se superponen viñetas en las que partes de la anatomía del trasunto literario de Grant Morrison se alternan con idénticas composiciones y escorzos de Flex Mentallo — especialmente significativa es la figura de las

\footnotetext{
9 Singer, M. Op. cit., p. 118.

10 Morrison, G. (2012), Op. cit., p. 317.

${ }^{11}$ Ibid., p. 321.
} 
manos mojadas por la lluvia a lo largo de los números que componen la serie- - Finalmente, el hecho de que exista una palabra mágica con efectos performativos es un elemento adicional que culmina en la alusión platónica de Lord Limbo al estipular que existe una fábrica personal e individual de ideas que dan forma a nuestro mundo: «Bienvenido a... ¿cómo deberíamos llamarlo? "De donde sacas tus ideas"». En este sentido, respecto de la relación del lenguaje con el pensamiento parece que Morrison abandona el planteamiento formulado en Kid Eternity, a saber, que el lenguaje es una factoría de la realidad.

Lo anteriormente expuesto parece vincularle a la concepción del lenguaje como vehículo del pensamiento. Esto es, el lenguaje no es solo un código de la realidad, puesto que las palabras tienen efectos performativos pero son consecuencia del pensamiento, de una fuente primordial que proviene de un horizonte supraempírico platónico. De este segundo horizonte de idealidad proviene la asociación inextricable entre palabra y pensamiento pues el lenguaje es la habilidad de vincular la segunda con el uso de la primera. Si la palabra mágica altera la realidad es debido a que el pensamiento funda esta última.

\section{All-Star Superman}

All-Star Superman es la relectura que Grant Morrison —acompañado nuevamente del dibujante Frank Quitely - elabora del célebre último hijo de Krypton. Con esta obra, ajena a la continuidad del Universo DC, Superman va a trascender y, como arquetipo solar, literalmente se convertirá en una estrella. El paradigma del superhéroe realizará doce trabajos, en un claro paralelismo con Hércules, que realizó doce tareas antes de ascender al firmamento. Como señala el propio guionista, Superman realiza el camino del héroe de Campbell, porque quiere recuperar al superhombre como parangón del desarrollo, de la excelencia. ${ }^{12}$ Todas ellas cualidades clásicas como la armonía, el equilibrio y la noble simplicidad. ${ }^{13}$

En este sentido, esta propuesta se nutre de una doble perspectiva desde la filosofía del lenguaje. En primer lugar, refiere la alusión a la simbología solar de índole platónica y hermética, que implica un camino de ascensión del que todos participamos - y este es el sentido último que concede Morrison a la conversión de Superman en un sol platónico, en la idea del heroísmo en sí y por sí-, pero que incluiría evidencias del realismo tomista. ${ }^{14}$

12 Ibid., pp. 476-477.

13 Tatarkiewicz, W. Historia de seis ideas. Arte, belleza, forma, creatividad, mímesis, experiencia estética. Madrid, Tecnos, 1987, pp. 212-215.

14 Santo Tomás de Aquino. La verdad. Pamplona, Cuadernos de Anuario Filosófico, 1996, pp. 17 y 18. 
En segundo lugar, en el universo en miniatura que protege el héroe, resulta relevante el surgimiento de un morador minúsculo que representa un émulo del filósofo humanista renacentista Giovanni Pico della Mirandola (1463-1494). Filósofo este que buscó alcanzar la síntesis de la filosofía antigua y medieval, quebrada tras la crisis del debate de los universales que iniciaría Ockham, y que aludiría incluso a la existencia de una sabiduría perenne y transhistórica. De hecho, el lenguaje podría responder a la unidad primigenia de la humanidad y a la búsqueda de la trascendencia. Por tanto, Morrison vincula someramente lenguaje con verdad pero también con ontología y metafísica en una obra de inspiración platónica.

\section{Klaus}

La propuesta filosófica de Klaus, a cuyo guion de Morrison acompañan las ilustraciones de Dan Mora, obra que presenta una versión nórdica de la figura navideña de Papá Noel, admite un desarrollo más exiguo pero no menos relevante en cuanto a su planteamiento gnóstico y neoplatónico. En este caso, Klaus se comunica con unas entidades gnóstico-herméticas de aspecto alienígena. Especialmente significativo es el hecho de que sea una melodía la que habilita el canal de comunicación. Melodía que recuerda poderosamente a la música de las esferas propia de órficos y pitagóricos. A mayor abundamiento, esa melodía permite que Klaus experimente saltos cognitivos y su estatuto epistemológico adquiera mayor vigor. Así, será capaz de acceder en varias ocasiones a un plano de formas geométricas y de ideas puras. La raigambre platónica es tan obvia que, en este caso, cabe aludir al traslado que hace Morrison de la filosofía del lenguaje a la cuestión de la verdad, de la relación entre nombre y hecho. ${ }^{15}$ Por tanto, el anclaje ontológico del lenguaje sobreabunda la semántica y ocupa el ámbito de la metafísica platónica.

\section{Metanarrativas y posmodernidad en el pensamiento de Grant Morrison}

Los distintos enfoques filosóficos desde los que Grant Morrison reflexiona sobre el lenguaje en este breve compendio de su obra escrita dan cuenta de un conocimiento teórico y de un modalismo que resultan coherentes con su sensibilidad posmoderna. ${ }^{16}$ Sus formas narrativas, en forma de guiones de cómic de superhéroes, hacen del autor un epígono sofisticado a través de recursos como la citada pluralidad de enfoques de filosofía del lenguaje, de la impugnación ontológica del realismo, la

15 Cabe aludir a fragmentos de obras platónicas como Sofista (253 a y 261 d) o Crátilo (389 d, 423 e y $435 \mathrm{~d})$.

${ }_{16}$ Para conocer con mayor profundidad el pensamiento postmoderno, vid. MAiz, R. y Lois, M. «Postmodernismo: La libertad de los postmodernos», en AnTón Mellón, J. Ideologías y movimientos políticos contemporáneos. Madrid, Tecnos, 1998, pp. 403-428. 
ruptura espaciotemporal y la crítica autorreflexiva del género superheroico. ${ }^{17}$ Una postmodernidad entendida como diagnóstico de un sistema en el que entran en crisis los elementos claves de la modernidad, en el que resulta imposible cualquier análisis histórico puesto que se ha alcanzado un punto más allá de la historia; en el que la autorreferencialidad, el solipsismo y la intertextualidad alcanzan el estatus de valores autónomos; el postestructuralismo ha impugnado las grandes narrativas, las pretensiones universales de validez y la racionalidad ilustrada al tiempo que la cultura postmaterialista y la tesis de la «diferencia» particularizan las prácticas políticas. ${ }^{18}$

Esta fragmentación del sujeto, su deconstrucción sistemática, será uno de los aspectos más posmodernos del pensamiento de Morrison. Baste como ejemplo el último número de Los Invisibles, en el que recurre a las personalidades múltiples - a través de economías psíquicas postmodernas evidenciadas en la «MeMePlexidad»—. ${ }^{19}$ Estos desafíos postestructuralistas hacia el lenguaje implicarían que la cadena inacabable de significantes estaría transida por la arbitrariedad y el convencionalismo.

Cabe añadir la incertidumbre epistemológica, en la obra de este autor, deudora de la intertextualidad como una multiplicidad de interrelaciones, préstamos e influencias. ${ }^{20}$ Por esta razón, resulta viable insertar en esta multiplicidad discursiva la defensa de la magia que realiza Grant Morrison. Autodenominado practicante de la magia operativa, que despliega efectos ontológicos, el autor asevera que añade nueva luz al mundo por medio del situacionismo y la práctica de la magia del caos: ${ }^{21}$ «Nosotros llevamos el rayo del significado y la importancia a la materia inconsciente, al papel en blanco, al cielo de la noche; ya somos magos divinos, ya somos superdioses». ${ }^{22}$ La magia del caos influiría, en consecuencia, en su cosmovisión metanarrativa del cómic.

De este modo, la magia que deviene posmoderna se erige en un elemento capaz de vertebrar esta dispersa epistemología posmoderna se convierte en un argumento adicional para afirmar la potencia ontológica del lenguaje, especialmente del nuevo lenguaje mítico y arquetípico que representa el superhéroe. Su caudal para cuestionar los cimientos de la realidad permite afirmar que el superheroísmo imprime un dinamismo posmoderno a lo ontológico y excede lo lingüístico.

${ }_{17}$ Singer, M. Op. cit., pp. 3 y 4.

18 Maiz, R. y Lois, M. Op. cit., pp. 403-405 y 423.

19 Singer, M. Op. cit., p. 132.

${ }^{20}$ Maiz, R. y Lois, M. Op. cit., p. 407.

${ }^{21}$ Morrison, G. (2003). Op. cit., pp. 16-25 y Atanes, C. Magia del caos para escépticos. Alicante, Dilatando Mentes Editorial, 2018, pp. 101 y 141-155.

${ }^{22}$ Morrison, G. (2012). Op. cit., pp. 481-482. 


\section{«Preparaos para volveros ficticios»: la relevancia del lenguaje para conocer la realidad}

La utilización ambivalente que Morrison realiza de diversas reflexiones filosóficas desde la semiótica y la semántica, junto con el propio carácter posmoderno de su pensamiento, permiten defender la relevancia filosófica y estratégica que el autor concede al lenguaje y que excede las lecturas ideológicas. El lenguaje puede ser vinculado con sus profundos efectos ontológicos como medio para desvelar la realidad. De esta manera, junto al acervo neoplatónico, deudor de su sensibilidad gnóstica y hermética, el lenguaje es operativo, genera efectos performativos. Se sitúa así en estrecha conexión con la magia operativa, en su vertiente de magia del caos, magia que informa buena parte de la producción literaria e intelectual de Morrison. Por tanto, por medio de la filosofía del lenguaje aborda postulados gnósticos y neoplatónicos pero también es una herramienta metodológica y epistemológica que excede el género literario del cómic de superhéroes para cuestionar los límites de la realidad. ${ }^{23}$

Los superhéroes son un caudal de conocimientos, de arquetipos y de ideas perennes. De ahí la cita que encabeza este apartado, pronunciada por Lord Limbo, el líder de la Legión de Legiones, en la serie Flex Mentallo, cuando los superhéroes han de abandonar el mundo real para guarecerse de una amenaza existencial en un mundo de ideas y reminiscencias imaginativas: «No es la muerte. Preparaos para volveros ficticios».

La palabra y el lenguaje aspiran a defender estas líneas, y guardarían entonces especial relación con el potencial superheroico: «La palabra mágica era un concepto que vinculaba al héroe con la base del discurso humano: el lenguaje, el relato». ${ }^{24}$ No en vano será una palabra mágica la que libere a los superhéroes de su exilio en el mundo inteligible de Flex Mentallo. La misma palabra que un célebre personaje de DC habría pronunciado para convocar su potencial sobrehumano durante décadas. Esta idea, que las palabras tienen poder, aparece señalada desde otra perspectiva en Los Invisibles. ${ }^{25}$ También en distintas formulaciones de la magia del caos parece encontrar Morrison la capacidad operativa del lenguaje para alterar la realidad-por medio de los sigilos (sellos) mágicos. ${ }^{26}$

El lenguaje también incluye un referente visual, icónico, algo que puede parecer, en primera instancia, contraintuitivo, pero que permite subsanar las inadecuaciones o

\footnotetext{
${ }_{23}$ Morrison, G. (2012). Op. cit.; Morrison, G. (2003). Op. cit. pp. 16-25. Cfr. Asprem, C. Op. cit., pp. 382-396 y Granholm, K. Op. cit., pp. 499-508.

${ }^{24}$ Morrison, G. (2012). Op. cit., p. 55.

${ }^{25}$ Neighly P. y Cowe-Spigai, K. Op. cit., p. 75.

${ }^{26}$ Morrison, G. (2003). Op. cit., pp. 18-20.
} 
aporías del propio lenguaje. ${ }^{27}$ De esta forma, Morrison es capaz de trazar los puntos de referencia de un círculo hermenéutico en los contenidos arquetípicos de los superhéroes. ${ }^{28}$ Lo hace evadiendo las diferencias entre signos verbales, escritos o visuales, pues estos son modalidades de significación que esquivan las ambigüedades del lenguaje. Buena muestra de ello es la Llave 17 que aparece en Los Invisibles.

A mayor abundamiento, los superhéroes en Flex Mentallo o en All-Star Superman personifican las aspiraciones más elevadas de la humanidad, sus mejores cualidades y su versión más luminosa. De esta manera generan significados. Morrison recurre a ellos - a sus actitudes, a sus poderes, a sus representaciones icónicas- para superar las abstracciones del lenguaje o las ambigüedades de metáforas y alegorías. ${ }^{29}$ Es un mecanismo simbólico, rayano en el lenguaje primigenio y originario que mimetiza la capacidad de este para demoler los límites de la materia, a juicio del dualismo gnóstico que parece subyacer en las obras de Morrison..$^{30}$ En Flex Mentallo, esta idea resulta acorde con la ontología gradualista de Hartmann y sus estratos, a saber: físico, orgánico o vital, psicológico y espiritual. Estas múltiples realidades, entre la que estaría la nuestra - debido a nuestro papel como lectores del cómic-, ${ }^{31}$ la del héroe en un estado espiritual o la del protagonista en un nivel vital, conformarían la fábrica de lo real, a través de la unidad de la superposición y sobrepujamiento de esas multiplicidades diversamente conformadas. ${ }^{32}$

De este modo, surge el recurso metanarrativo y posmoderno de Morrison, conectar el mundo de las ideas, el de los superhéroes y el nuestro, lo que permite que el caudal arquetípico superheroico atraviese las barreras de la realidad. Consecuentemente, dicho paradigma sobreabunda las dimensiones de la filosofía del lenguaje para presentar un modelo multifacetado y de calado teórico.

\section{El superhéroe para Morrison. Multidimensionalidad de un concepto}

Como hemos comprobado, a través del lenguaje las cuestiones filosóficas planteadas inciden en el concepto que Morrison maneja del superhéroe. Nacido en mitad

27 Singer, M. Op. cit., p. 15.

${ }^{28}$ Riva G. y Vilar, M. «Hermenéutica y apophenia. El Batman de Grant Morrison y el delineado del Círculo Hermenéutico», en Revista Luthor n. ${ }^{\circ} 6$ (2011), pp. 7-9.

${ }^{29}$ Singer, M. Op. cit., p. 16.

30 Morrison, G. (2003). Op. cit., p. 23.

31 Torralba, J. «Flex Mentallo: La historia metaficcional de los superhéroes», Zona Negativa, 27 de junio de 2008. Disponible en: http://www.zonanegativa.com/?p=5618 (consultado el 2 de diciembre de 2013).

32 Hartmann, N. Ontología. Volumen III. La fábrica del mundo real, México D. F., Fondo de Cultura Económica, 1959, p. 220. 
de una explosión de color y de acción, el superhéroe es una nueva creencia que ha conquistado el mundo, la reminiscencia de un dios prototípico que lucha una épica batalla para librarnos del abismo existencial al que nos convoca su gemelo oscuro. ${ }^{33}$ Sería una figura axial de la narrativa de este género del arte secuencial. Gracias a sus personalidades secretas, su prosa humana enmascara la poesía de su existencia dentro de un universo de aventuras míticas e interrelaciones complejas. El superhéroe es, por tanto, (a) mitología, pero también (b) arquetipo y, como referente moral, (c) concepto normativo. Además, es objeto de estudio filosófico (d).

Para comenzar, el héroe mitológico (a), como genealogía, etimológicamente conduce al herós o hemitheos de la antigüedad clásica, al linaje solar de semidioses y personajes singulares, al canon estético que conjuga perfección física y poder anatómico en vigorosas retóricas corporales del culto al cuerpo. ${ }^{34}$ Así, en All-Star Superman, Morrison vincula al último kriptoniano con el mito solar en una miscelánea de resonancias platónicas al tiempo que le eleva a la apoteosis tras realizar un trayecto épico de ascensión de la mera humanidad para integrarse en el orden divino: ${ }^{35}$

Este hombre de Vitrubio con capa, nuestro Superman restaurador, intentaría destilar la esencia pura de la mejor creación de la cultura popular, un alma de superhéroe tan fuerte, $\tan$ noble, tan inteligente y tan llena de recursos que no le haría falta matar para lograr sus objetivos [...] para recordarnos que bajos nuestras camisas, a la espera, siempre hay una explosión de color, un rayo estilizado, un corazón ardiente... era un Hombre Cualquiera divino, un hombre platónico que resudaba el drama de la vida ordinaria sobre un lienzo extraordinario. ${ }^{36}$

Encontramos en este Superman tres características que, a juicio de Nagy, destacaban en los materiales míticos de los héroes más grandes de los aqueos - Aquiles y Ulises-, a saber: kleos, o gloria épica; nostos, la narración sobre el regreso al hogar; y las visiones poéticas de la inmortalidad (física, espiritual o cultural). ${ }^{37}$ Hace acto de presencia en el pensamiento de Morrison, para quien los superhéroes son modelos utópicos inmunes a la deconstrucción e invulnerables al paso del tiempo:

Con Superman y los demás superhéroes, el ser humano creó unas ideas invulnerables a todo daño, inmunes a la deconstrucción, elaboradas para superar a los genios diabólicos,

33 Morrison, G. (2012). Op. cit., p. 21.

34 Gasca, L. y Gubern, R. El discurso del cómic. Madrid, Cátedra, 2011 [1988], p. 49.

35 Vid. All-Star Superman, n. ${ }^{\text {os }} 1$ y 12, especialmente la resonancia platónica de la cercanía solar de Superman como aquel que contempla y se acerca, en un camino ascendente, al propio astro rey.

36 Morrison, G. (2012). Op. cit., pp. 475-476.

${ }^{37}$ Nagy, G. The best of the Achaeans. Concepts of the Hero in Archaic Greek Poetry. The Johns Hopkins University. Disponible en: http://www.press.jhu.edu/books/nagy/BofATL/chapter9.html (consultado el 18 de enero de 2014). 
concebidas para hacer frente al Mal en estado puro y, de alguna manera, y contra todo pronóstico, salir siempre vencedoras [...]. ¿No será que nuestra cultura, privada de imágenes optimistas de su propio futuro, se ha dirigido a la fuente primaria en busca de modelos utópicos? ¿No será que el superhéroe, con su capa y su traje ajustado, es en estos momentos la mejor representación de aquello en lo que podríamos convertirnos si nos empezásemos a sentir dignos de un mañana en el que nuestras mejores cualidades sean lo bastante fuertes como para superar los impulsos destructivos contra el proyecto humano? ${ }^{38}$

Morrison nos sitúa ante un caudal de pensamiento mítico y simbólico, pues ¿̨no existiría mayor mito que Papá Noel, que Morrison habría elevado a la apoteosis alienígena del superhéroe que salva al mundo? Tal es la premisa de su serie Klaus, al vincular al naturista antecedente de Santa Claus con inteligencias alienígenas neoplatónicas y herméticas que culminan en el héroe poderoso, amable y noble que nos da a conocer su autor.

Esta vertiente admite conexión con el optimismo antropológico del humanista neoplatónico Pico della Mirandola y su Discurso sobre la dignidad del hombre, con su nuevo modelo de pensamiento y de reflexión, que desvincula a la persona de su ambiente para aspirar a la decisión de quién ser y qué hacer. ${ }^{39}$

Prosigamos entonces nuestro análisis con otra dimensión, la del superhéroe arquetípico (b), con su vocación perenne como modelo, imagen y símbolo ideal y ancestral. Trayecto que Joseph Campbell desmenuzó en un ciclo perenne - la partida, la iniciación y el regreso-.${ }^{40}$ Cuando finaliza el largo camino, el héroe habrá alcanzado su sol, el símbolo astrológico que denota el cumplimiento del potencial interior. En última instancia, «la hazaña del héroe moderno debe ser la de pretender traer la luz de nuevo a la perdida Atlántida del alma». ${ }^{41}$

Por ejemplo, All-Star Superman reproduce, casi miméticamente, el esquema de Joseph Campbell. Este camino del héroe, de su origen, su desafío y ascenso a la gloria, lo plantearía el propio Grant Morrison, años antes, por medio del joven protagonista de The Invisibles, el iluminado Jack Frost. A lo largo de la colección, en sus tres volúmenes comprobamos cómo el joven rebelde y antisistema evoluciona hasta abrazar su responsabilidad como redentor y líder profético-escatológico del Colegio Invisible. En definitiva, para Morrison, los héroes nos retrotraen a la edad de oro perdida en la noche de los tiempos. ${ }^{42}$

\footnotetext{
${ }^{38}$ Morrison, G. (2012). Op. cit., p. 15.

39 Ibid., pp. 479-482.

${ }^{40}$ Campbell, J. El héroe de las mil caras. Psicoanálisis del mito. México D.F., Fondo de Cultura Económica, 1959, pp, 53-232.

${ }^{41}$ Ibid., p. 342.

${ }^{42}$ Morrison, G. (2012). Op. cit., p. 35.
} 
Finalmente, el superhéroe sería una categoría normativa (c) a través de los uniformes emblemáticos y los ropajes coloridos se actualizaría un enfrentamiento maniqueo entre el bien y el mal. ${ }^{43} \mathrm{El}$ héroe nos permite atisbar el mundo tal y como debería ser, fuente de inspiración y, en consecuencia, deviene concepto normativo. ${ }^{44}$ Así lo atestigua en todos aquellos personajes del universo DC que él guioniza. Por ejemplo, la Liga de la Justicia, a lo largo de los tres años en los que se encargó de dicha serie (1997-2000), recuperaría su grandeza heroica y su carácter de panteón de semidioses del bien en conflicto con la oscuridad. Realizar un resumen de dicha etapa sería extenso y prolijo, pero baste citar el carácter de sus aventuras y la resolución a las mismas, siempre gracias a la nobleza y la astucia como quintaesencia de la justicia: «Debería resultarnos esperanzadora la proliferación de las historias de superhéroes, pues ellos son la señal luminosa y temblorosa de la necesidad de avanzar, de imaginarnos nuestra mejor versión, la más justa, la más decidida». ${ }^{45}$

No obstante, la multidimensionalidad del concepto no se circunscribe única y exclusivamente a estas dimensiones que citamos. Los materiales heredados del repertorio heroico han fluido en el pensamiento de Morrison. Por esta razón, pensar discursiva y estéticamente el cómic de superhéroes precisa recuperar también algunas de las raíces que han alimentado filosóficamente la multidimensionalidad del superhéroe (d).

Comenzaré por el «Problema XXX» de la Metafísica, atribuido a Aristóteles, en el que aparece una pregunta que marcará con profusión la obra de Morrison en particular, así como las reflexiones sobre los superhéroes en general: «¿Por qué razón todos aquellos que han sido hombres de excepción [...] resultan ser claramente melancóli$\cos ? »{ }^{46} \mathrm{El}$ superhéroe es entonces superior a los demás porque contiene todas las potencialidades gracias a una adecuada proporción de su misteriosa singularidad. ${ }^{47}$ No obstante, en caso de desequilibrio, el héroe puede caer en extremos de inestabilidad, en una prueba de carácter existencial. En su autarquía o autosuficiencia, el héroe - el hombre excepcional (megalopsychos) — vincula justicia y amistad merced a su círculo de aliados.

Ahora bien, también subyace una idea propia de Nietzsche. El hombre bueno es el que conserva su poder. Por tanto, bondad, poder y moral resultan concomitantes. El superhombre ejerce como tal porque los demás no lo hacen. Así lo reconoce Zaratustra: «Yo soy un anunciador del rayo y una pesada gota que cae de la nube: mas ese rayo

${ }^{43}$ Gasca, L. y Gubern, R. Op. cit., p. 68.

${ }^{44}$ Loeb, J. y Morris, T. «Héroes y superhéroes», en Morris, T. y Morris, M. Los superhéroes y la filosofía. Barcelona, Blackie Books, 2010, p. 40.

45 Morrison, G. (2012). Op. cit., p. 480.

46 Aristóteles. El hombre de genio y la melancolía. Problema XXX. Barcelona, Acantilado, 2007, pp. 46 y 47.

47 Ibid., p. 103. 
se llama superhombre». ${ }^{48}$ También sería estético, pues el superhombre conjura apolíneamente la destrucción dionisiaca. ${ }^{49}$ Tal sería, para Morrison, la dualidad contenida en el dúo de los mejores superhéroes del mundo - Batman y Superman, dionisíaco el primero y apolíneo el segundo-.${ }^{50}$ Solo el superhéroe, nos recuerda Morrison en su Final Crisis, es capaz de demoler la superestructura con la potencia ontológica de su existencia, con el relámpago y la demencia.

Finalmente, también resulta posible vincular a la libertaria Ayn Rand con Morrison por medio de rasgos como la defensa de la libertad individual, la certeza moral y la desconfianza en los poderes públicos. En palabras del protagonista de Himno, «mi hogar se convertirá en la capital de un mundo en el cual cada hombre será libre de existir para su propia causa». ${ }^{51} \mathrm{El}$ relato de Flex Mentallo, a través del cual Morrison teje una compleja narración no lineal, fracturada y metareferencial, es en última instancia una apología del héroe solo en su búsqueda de algo mucho mayor que él mismo. ${ }^{52}$

\section{Conclusiones}

Es posible comprobar que Grant Morrison es conocedor del ámbito de la filosofía del lenguaje y de los ámbitos de semiótica y semántica. En su producción literaria y artística desempeñan un papel auxiliar, que permite profundizar en su acervo esotérico, perennialista y posmoderno. No obstante, la ambivalencia y ambigüedad con la que plantea distintas premisas y enfoques de este ámbito filosófico no son accesorios o secundarios. Representan una vía para exponer interrogantes ontológicos y cuestionar las epistemologías más asentadas desde la modernidad.

Por todo ello, el superhéroe es un elemento más de ese lenguaje que emplea Grant Morrison para interpelarnos en la búsqueda de los límites ontológicos y cuestionar el estatuto de nuestra epistemología. Los superhéroes son más que meros personajes de cómic: son una senda de la ascensión para alcanzar el mundo en sí. En palabras del propio Morrison: «En una cultura laica, científica, racional y falta de un liderazgo espiritual convincente, las historietas de superhéroes hablan alto y claro a nuestros mayores miedos, a nuestros anhelos más profundos y a nuestras más altas aspiraciones». ${ }^{53}$

${ }^{48}$ Nietzsche, F. Así habló Zaratustra. Un libro para todos y para nadie. Madrid, Alianza Editorial, 1997 [1885], p. 40.

49 Cfr. Marchán Fiz, S. La estética en la cultura moderna. Madrid, Alianza Editorial, 1987, pp. 212215.

50 Morrison, G. (2012). Op. cit., pp. 21-47.

51 Rand, A. Himno. Buenos Aires, Grito Sagrado Editorial, 2009 [1938].

52 Por ejemplo, en el segundo número de la serie, Flex Mentallo está dispuesto a conceder poderes cuasi divinos a un drogadicto agonizante con tal de salvar su vida.

53 Morrison, G. (2012). Op. cit., p. 18. 


\section{Bibliografía}

Aristóteles. El hombre de genio y la melancolía. Problema XXX. Barcelona, Acantilado, 2007.

Atanes, C. Magia del caos para escépticos. Alicante Dilatando Mentes Editorial, 2018.

Ball, T., Dagger, R. y O’Neill, D. Political Ideologies and the Democratic Ideal. Boston, Pearson, 2014.

Campbell, J. El héroe de las mil caras. Psicoanálisis del mito. México D.F., Fondo de Cultura Económica, 1959.

Conesa, F. y Nubiola, J. Filosofía del lenguaje. Barcelona, Herder, 2002.

Eccleshall, R. et al. Political Ideologies. An Introduction. Londres, Routledge, 1994 [1984].

García-Santesmases, A. «Los socialismos», en Quesada, F. (ed.). Ciudad y ciudadanía. Senderos contemporáneos de la flosofía política. Madrid, Editorial Trotta, 2008, pp. 31-47.

Gasca, L. y Gubern, R. El discurso del cómic. Madrid, Cátedra, 2011 [1988].

Hartmann, N. Ontología. Volumen III. La fábrica del mundo real. México D. F., Fondo de Cultura Económica, 1959.

Llano, A. Teoría del conocimiento. Madrid, Biblioteca de Autores Cristianos, 2015.

Maiz, R. y Lois, M. «Postmodernismo: La libertad de los postmodernos», en ANTón Mellón, J. Ideologías y movimientos políticos contemporáneos. Madrid, Tecnos, 1998.

Marchán Fiz, S. La estética en la cultura moderna. Madrid, Alianza Editorial,1987.

Molina, I. Conceptos fundamentales de Ciencia Politica. Madrid, Alianza Editorial, 1998.

Morris, T. y Morris, M. Los superhéroes y la filosofía. Barcelona, Blackie Books, 2010. 
Morrison, G. Pop Magic! en Metzger, R. (ed.). Book of Lies. The Disinformation Guide to Magick and the Occult. Nueva York, Disinformation, 2003, pp. 16-25.

—Supergods. Héroes, mitos e historias del cómic. Madrid, Turner, 2012.

—et alii. Los Invisibles, vol. 1-7. Barcelona, ECC Cómics, 2015-2016.

—et alii. Animal Man, vol. 1-3. Barcelona, ECC Cómics, 2020.

—y Fegredo, D. Kid Eternity. Barcelona, ECC Cómics, 2019.

—y Mora, D. Klaus. Barcelona, ECC Cómics, 2017.

-y Quitely, F. All-Star Superman. Barcelona, ECC Cómics, 2013.

—y Quitely, F. Flex Mentallo. Barcelona, ECC Cómics, 2019.

Neighly, P. y Cowe-Spigai, K. Anarchy for the Masses. The Disinformation Guide to The Invisibles. Nueva York, Disinformation, 2003.

Nietzsche, F. Así habló Zaratustra. Un libro para todos y para nadie. Madrid, Alianza Editorial, 1997 [1885].

Quine, W. O. Palabra y objeto Barcelona, Labor, 1968.

Rand, A. Himno. Buenos Aires, Grito Sagrado Editorial, 2009 [1938].

Riva, G. y Vilar, M. «Hermenéutica y apophenia. El Batman de Grant Morrison y el delineado del Círculo Hermenéutico», en Revista Luthor n. 6 (2011), pp. 1-9.

Santo Tomás de Aquino. La verdad. Pamplona, Cuadernos de Anuario Filosófico, 1996.

Singer, M. Grant Morrison. Combining the Worlds of Contemporary Comics. Jackson, University Press of Mississippi, 2012.

Tatarkiewicz, W. Historia de seis ideas. Arte, belleza, forma, creatividad, mimesis, experiencia estética. Madrid, Tecnos, 1987.

Whorf, B. L. Lenguaje, pensamiento y realidad. Barcelona, Barral, 1971. 